\title{
A "HISTÓRIA GERAL DA NATUREZA E TEORIA DO CÉU" DE IMMANUEL KANT: SUA IMAGEM DE COSMOS E SEU CLAMOR POR UMA GEOGRAFIA FÍSICA
}

\section{The Immanuel Kant's “General History of nature and theory of heaven": His Image of Cosmos and his Clamour for a Physical Geography}

\author{
Antonio Carlos Vitte \\ Doutor em Geografia Física, Assistente Doutor da Universidade Estadual de Campinas \\ Instituto de Geociências, Unicamp. Campinas (SP) \\ acarlosvitte@uol.com.br \\ Alexandre Domingues Ribas \\ Doutor, Instituto de Geociências, Unicamp. Campinas (SP) \\ alexecris2001@hotmail.com
}

Artigo recebido em 17/12/2012 e aceito para publicação em 30/01/2013

RESUMO: Em março de 1755, vinha a público, simultaneamente em Leipzig e em Königsberg (e sob a edição de Johann Friedrich Petersen), a "História Geral da Natureza e Teoria do Céu”; opúsculo de Immanuel Kant (1724-1804) conspícuo e inexcedível filósofo alemão - que exibe a sistematização maior de sua denominada cosmologia pré-crítica. Poucos meses depois, mais designadamente no semestre de verão de 1756, o mesmo Kant começa a lecionar um curso de geografia física. Parece-nos ser inconcusso que há uma abastada consangüinidade entre o nascedouro das perquirições geográficas em Kant e essas meditações cosmológicas (e cosmogônicas) de 1755 - devotadas a alcançar uma representação concreta do universo em sua totalidade $\mathrm{e}$, outrossim, um fundamento metafísico de explicação da natureza.

Palavras-chave: cosmologia, geografia física, espaço, natureza, teleologia.

ABSTRACT: In March 1755, came to public, both in Leipzig and Königsberg (under edition of Johann Friedrich Petersen), the "General History of Nature and Theory of Heaven"; booklet from Immanuel Kant (1724-1804), a conspicuous and outstanding German philosopher, who showed the largest systematisation of his named pre-critical cosmology. A few months later, most notably in the summer semester of 1756, Kant himself begins to teach a course in physical geography. It seems to be undeniable that there is an affluent consanguinity amongst the rising of geographical enquiries concerning Kant and these cosmological (and cosmogonic) meditations of 1755 . These ones were devoted to achieving a concrete representation of the universe in its entirety and, likewise, a metaphysical fundament of nature explanation.

Keyword: cosmology, physical geography, space, nature, teleology 


\section{INTRODUÇÃO}

O objetivo deste artigo é estabelecer algumas relações entre a obra de Immanuel Kant, publicada em 1755, "História Universal da Natureza e Teoria do Céu" (Allgemenine Naturgeschichte und Theorie des Himmels) e suas reflexões sobre a geografia física. Para tal trabalho introdutório devemos alertar que o mesmo é um trabalho arqueológico, primeiramente devido à escassa bibliografia filosófica tratando da obra "A História Geral", que é subutilizada e pouco estudada pelos filósofos kantianos, muito por ser considerada uma obra advinda ainda da fase pré-crítica, em que o jovem filósofo Kant por não ter ainda um sistema filosófico desenvolvido faria uso de variadas fontes filosóficas e conceituais, que o colocaria ainda como dogmático. Outra questão que deve ser colocada é a também escassa bibliografia especializada no campo da Geografia, sobre a noção de geografia física de Kant e como esta se desenvolveu ao longo de seus quarenta anos de magistério e trabalho filosófico.

No primeiro caso, Campo (1953, p. 222) se pergunta: "como è possible parlare di critica in um período precritico?". No segundo caso, acreditamos que a vaguidade com que são tratadas as relações entre Kant e a Geografia deve-se sobremodo a perspectivas limitantes com que é abordado o conteúdo de história do pensamento geográfico nos cursos de Geografia no Brasil e a manuais que se preocuparam em cristalizar uma visão temporal e panorâmica sobre a Geografia, do que propriamente tratar de temas epistemológicos, que necessitaria nesta empreitada de um diálogo mais próximo da filosofia. Portanto, podemos falar em uma epistemologia da Geografia se a própria história e arqueologia dos conceitos geográficos não são realizadas pelos geógrafos?

\section{IMMANUEL KANT: BREVES CONSIDERAÇÕES SOBRE SUA TRAJATÓRIA ATÉ 1755}

Kant ingressou na Universidade de Königsberg em setembro de 1740, onde permaneceu até 1746 e frequentou as lições de matemática e ciências da natureza, de teologia, de filosofia e de letras clássicas latinas. Quando de sua estada na Albertina, a Europa savante acusava a peremptória derrocada da física cartesiana por sorção do triunfo categórico do newtonianismo. E o eminente professor Martin Knutzen (17131751), um discípulo de Christian Wolff (1697-1754), foi quem prestou ao púbere Immanuel os prolegômenos da filosofia natural de Isaac Newton (1642-1727).

Todavia, essa acolhida da ciência newtoniana, por parte de Kant, não se cumpriu desprendidamente de uma atmosfera intelectual povoada pelas aporias legadas pela física de René Descartes (1596-1650), pela metafísica de Christian Wolff e pela filosofia de Leibniz (1646-1716). E, açulado por este ambiente tão sedicioso, Kant redigiu seu "Pensamentos sobre a verdadeira apreciação das forças vivas"; texto que teve sua impressão iniciada em 1746 (mas cuja publicação somente se sucedeu em 1749) e que se absorve numa controvérsia ao redor do problema da medida das forças (cingindo o conceito leibniziano de força e as injúrias, a ele, incididas da concepção geométrica de Descartes e da prescrição nodal da mecânica de Newton).

Teve requinte o acaso que, no ano em que encetara a impressão desse seu escrito primogênito, Kant deparasse-se impelido a abdicar da Universidade, antes, inclusive, de ter auferido todos os seus títulos acadêmicos. E, para ganhar a vida, ele se prontificou - como era usual para os cultos sem recursos dessa época - a preencher o ofício de preceptor de famílias ricas tanto de Königsberg como de seus arrabaldes. 
Kant desempenhou, "[...] por la presión de las circunstancias materiales [...]" (CASSIRER, 1997, p. 47), a dignidade de aio por cerca de nove anos, ou seja, de 1746 a 1755. E foi nessa intermitência de tempo que ele, decerto, escreveu sua "História Geral da Natureza e Teoria do Céu"; que apareceu, inominadamente, em março de 1755, em Leipzig e em Königsberg, à sombra da edição de Johann Friedrich Petersen.

Também em 1755, Kant aquilatando-se proprietário de "[...] una mirada intelectual libre y un juicio maduro sobre la totalidad de los problemas científicos [...]" (CASSIRER, 1997, p. 50) e experimentando "[...] una sensación de seguridad interior y exterior [...]" (CASSIRER, 1997, p. 50) - decide por retrogradar à Universidade de Königsberg. $\mathrm{E}$, posteriormente à defesa de duas dissertações latinas, ele emprega-se, a partir do outono de 1755, a ser "[...] 'magister legens', correspondente ao atual 'Privatdozent', que não recebe um salário do Estado e vive dos ganhos da livredocência e das aulas particulares para estudantes" (HÖFFE, 2005, p. 8-9).

De 1755 a perto de 1796, Kant administrou (seja em preleções particulares, seja em conferências públicas) cursos (cuja audiência era constituída por uma miscelânea de prussianos e estrangeiros: notadamente bálticos, russos e polacos) destinados aos campos do saber os mais variados: lógica, metafísica, ética, antropologia, física teórica, matemáticas, direito, enciclopédia das ciências filosóficas, pedagogia, mecânica, mineralogia, teologia etc. E, em meio a disciplinas versadas tão multíplices, que incluíam "[...] both philosophical and nonphilosophical topics" (ELDEN, 2008, p. 3), Kant oblatou - por "[...] forty-nine times over a forty-year period from 1756 to 1796 - more frequently than any of his other topics other than logic and metaphysics [...]" (ELDEN, 2008, p. 3) e, muito provavelmente, sobressaltado pela ocorrência do Terremoto de Lisboa (que pôs em ênfase a questão da ordem e da finalidade da natureza) - o ensino de geografia física ${ }^{1}$. Por que Kant pôs-se a doutrinar um curso de geografia física? Nos ecos da imagem de cosmos que ele acastela em sua "Teoria do Céu" habita, assim apostamos, um de seus motores basilares.

\section{KANT PRÉ-CRÍTICO}

A chamada fase pré-crítica de Kant vai até 1781 quando é publicada a Crítica da Razão Pura. Segundo pesquisadores, a fase pré-critica é composta por várias questões e orientações intelectuais, mas é justamente esta fase pré-crítica que instiga a análise do pensamento de Kant já na fase crítica, pois o mesmo passou, segundo o autor, por três importantes etapas: a racionalista, a empirista e a crítica.

Genericamente, podemos dividir a fase pré-crítica de Kant em dois momentos que se estende de 1746 a 1770, cujo marco é a obra "Acerca da forma e dos princípios do mundo sensivel e inteligível", também conhecida como a Dissertação de 1770 . Na fase de 1755 , marcada pela forte influencia de Leibniz e a outra que se inicia em 1763, o jovem filósofo passa a tomar contato com os trabalhos de David Hume, passando a se interessar pela crítica à metafísica dogmática a partir da prova ontológica da existência de Deus, desembocando em 1766 com uma crítica estruturada à metafísica $\mathrm{e}$ suas provas supra-sensíveis. Segundo Torretti (1980, p.40), a fase pré-crítica e a crítica estão unidas e ao mesmo tempo separadas pela Dissertação de 1770 .

Esta variação no pensamento de Kant talvez possa ser explicada pelo próprio momento histórico da filosofia e das ciências de uma maneira geral. Isto por que a filosofia alemã, a partir de meados do século XVIII, não consegue mais explicar as teses metafísicas de modo aprofundado, 
uma vez que neste período a busca é a de construção de uma filosofia científica, voltada ao próprio empirismo mecânico, culminando em um primeiro momento para o empirismo inglês e francês. No jovem filósofo Kant, esta problemática se expressa em um racionalismo que não despreza o empírico, mas também critica a razão dentro de seu próprio racionalismo, buscando assim, estabelecer os seus limites, utilizando-se para isto do recurso da experiência para prescrever a objetividade real dos conceitos racionais.

O racionalismo da época aplicava a razão à realidade das coisas, com a seguinte tarefa: a partir da experiência, a razão deveria encontrar a causa última das coisas por meio do princípio dessas coisas, demonstrando por si mesma a existência delas.

Já a partir da década de 1760, genericamente marcada por reflexões que hostilizam a metafísica, entre elas o nominalismo, o humanismo, o empirismo psicológico e a ciência experimental; Kant passa a se preocupar com os problemas que enfraqueciam a filosofia, desembocando assim em uma crítica à razão. É neste contexto, que o filósofo sofrerá influência de Hume e Newton e se colocará categoricamente contrário ao dogmatismo da razão.

Para tanto, estaremos encentrando nossa diligência em esquadrinhar, particularmente, a cognação existente entre a idéia de cosmos glorificada por Immanuel Kant em sua "História Geral da Natureza e Teoria do Céu" (1755) e a gênese do curso de geografia física que o então Magister de Königsberg principia a instrução em 1756.

\section{A "HISTÓRIA GERAL DA NATUREZA E TEORIA DO CÉU" E SUA IMAGEM DE COSMOS}

A problemática (ou a dúvida) cosmológica persiste, perdura (e se reinventa) “[...] dans l'oeuvre de Kant [...] à travers les étapes successives qui jalonnent l'évolution de sa pensée" (SEIDENGART, 1984, p. 12), tanto "[...] dans sa partie précritique que dans sa partie critique [...]" (KERSZBERG, 1984, p. 207); e o seu julgamento, assim acreditamos, permitenos "[...] d'éclairer non seulement la genèse du criticisme, mais également le sens de l'orientation ultérieure de sa philosophie transcendantale en quête d'unité et d'achèvement" (SEIDENGART, 1984, p. 12). Esse seu corpulento vigor provém do inexaurível e úbere desejo de Kant em "[...] relier indissolublement la Métaphysique de la Nature à la physique" (SEIDENGART, 1984, p. 12).

E essa sua veleidade se debuta em sua cosmologia pré-crítica, da qual os traçamentos basilares são apresentados (sobretudo, escrupulosa e poeticamente) em sua "História Geral da Natureza e Teoria do Céu" (1755) - trabalho científicoliterário que jamais angariou (arrecadou) "[...] suffisamment [...] toute l'attention qu'elle mérite et figure comme une grande oubliée de l'histoire" (SEIDENGART, 1984, p. 9).

Em sua "Teoria do Céu", Kant aloca em ajuizamento uma espécie de avaliação (especulativa e epistemológica) referente ao estatuto (e ao abarcamento) das leis físicas de Newton e de seu caráter universal (isto é, de sua envergadura em envolver a natureza em seu conjugado). Portanto, direcionando sua agudeza a perscrutar os termos da significação metafísica da experiência (e a excogitar, por decorrência, sobre o enraizamento entre a ciência física e a filosofia), Kant, nessa sua obra de 1755, dedica-se à investigação do limite físico das leis físicas newtonianas e, por efeito, da possibilidade de generalização a todo universo da única experimentação local.

Nesse sentido, é em sua "Teoria do Céu" que Kant, ultrapassando as demarcações de um positivismo estreito, dispõe-se, por primeira vez, a solucionar 
(versar), metafisicamente, a inseparabilidade entre a física e os seus fundamentos, visto que, nesse seu poema cosmológico - além de aplicar-se em “[...] montrer que l'essence même de la nature doit être recherchée dans son histoire" (KERSZBERG, 1984, p. 209) - Kant intenciona clarificar "[...] non seulement la structure totale du monde (dans l'espace et dans le temps indissociés), mais aussi la nature profonde des lois physiques; l'une n'est plus séparable de l'autre [...]" (KERSZBERG, 1984, p. 209).

Não hesitamos, entretanto, em certificar que a peculiaridade (a singularidade) mais acentuada da "Teoria do Céu" consiste em que, nas suas páginas, Kant - não obstante executar uma "[...] construction spéculative limitée principalement au cadre de la mécanique newtonienne [...]" (KERSZBERG, 1984, p. 208) e de governar suas idéias "[...] fort proches de celles de Newton sur le plan 'technique' [...]" (KERSZBERG, 1984, p. 209) - não se priva da prerrogativa de raciocinar o que a "[...] science newtonienne n'a cherché à traduire que dans les limites de cette seule expérience" (KERSZBERG, 1984, p. 209) e o que Newton, ele mesmo, ao menos nos "[...] ses travaux publiés, s'est toujours refusé à penser dans les termes de sa propre physique mathématique. Il s'agit de la cause finale, d'où doit procéder toute notre expérience immédiate [...]" (KERSZBERG, 1984, p. 209).

Assim sendo, é por buscar combinar a causalidade final (teleológica) e a causalidade mecânica com a ambição de instaurar uma representação concreta de todo o universo (em sua estrutura e em sua história) - e, com isso, exceder as raias firmadas pela metodologia da filosofia experimental de Newton (radicada na requisição de uma visão diametralmente indutivista do mundo) e caminhar por sobre os seus embaraços e dificuldades cosmológicas - que a "Teoria do Céu”, sem embargo seus salientes tributos científicos (em física, mecânica celeste, matemática etc.), estaca raízes em um chão movediço e atreve empreender, numa frágil conjectura, uma viagem perigosa aos recantos sombrios onde se encruzam o físico e o miraculoso, o teológico e o científico, o positivo e o metafísico, a razão teórica e a razão prática, o teleológico e o moral.

Não por eventualidade, Kant consciente dos riscos em se interceder a discórdia aparente que colocava em incompatibilidade, no instante da alumiação da formação do universo, o Naturalista e o causídico da Religião - abre sua "Teoria do Céu" confidenciando: "J'ai choisi un sujet qui, tant par sa difficulté intrinsèque qu'en ce qui concerne la religion, peut dés l'abord prévenir défavorablement une grand partie des lecteurs" (KANT, 1984, p. 65). Pôr-se a antever, favorecendo-se dos princípios de Newton, a coordenação e a origem do mundo (a constituição dos corpos celestes e a ascendência de seus movimentos) em sua soma como sendo efeito de leis puramente mecânicas (de uma natureza deixada a ela mesma) poderia denotar a ação de um abolucionista do governo divino, ou, o feito de um insolente que se atira em impulsos que "[...] semblent dépasser de très loin les forces de la raison humaine" (KANT, 1984, p. 65). E Kant tinha a perfeita noção desse arrojo: "Je vois bien toutes ces difficultés, et cependant je ne perds pas courage. Je ressens toute la force des obstacles qui s'opposent et cependant je n'abandonne pas" (KANT, 1984, p. 65).

Após convencer-se da severa anuência entre o seu sistema e a religião; acautelando-se "[...] à ne rien affirmer qui se soit en accord avec l'enseignement de la religion chrétienne [...]" (SEIDENGART, 1984, p. 31) e sentindo "[...] une tranquilité inébranlable" (KANT, 1984, p. 66) para lograr exceder o que havia de unilateral entre as focagens (ambas ineptamente culminantes) do homem de fé e do homem 
de ciência, Kant - escorando-se, largamente, no princípio heurístico da analogia, que lhe concede abarcar o "[...] Tout au moyen de la partie, de la même façon dont, en mathématiques, on peut penser dans sa totalité une suite infinie de termes grâce à la foi de formation qui les engendre tous" (SEIDENGART, 1984, p. 44) - se lança à ideação de uma imagem de cosmos, que não é outra coisa senão o produto de uma natureza que, per si (e estimulada por uma ordem que lhe é impressa pela sabedoria divina no ato da Criação), se molda (se afeiçoa e se desenvolve) mecanicamente.

É, pois, atrelando a causalidade mecânica com a teleologia monadológicajá que "[...] Dieu a mis dans les forces de la nature un art secret qui lui permette de se former d'elle-même à partir du chaos en une parfaite constitution du monde [...]" (KANT, 1984, p. 72) - quer dizer, é reconciliando o "[...] mécanisme et la finalité sur le terrain nouveau d'une physico-théologie rénovée où le physique et le théologique se renforcent mutuellement au lieu de se repousser obstinément" (SEIDENGART, 1984, p. 30) que Kant transfere vida ao seu "système du monde". Como ele próprio assevera: a matéria que se "[...] détermine selon ses lois les plus générales produit par un processus naturel [...] des conséquences convenables [...] qui semblent être le projet d'une sagesse suprême" (KANT, 1984, p. 68).

Admitir que o mundo "[...] avec tout son ordre et toute sa beauté, est seulement un effet de la matière laissée à ses lois générales de mouvement [...]" (KANT, 1984, p. 65) - pois que a “[...] mécanique aveugle des forces de la nature a le pouvoir de se développer à partir du chaos de façon si splendide et [...] atteint d'elle-même à une telle perfection [...]" (KANT, 1984, p. 65) - só faz, ao avesso de invalidar, '[...] apparaître avec l'éclat le plus vif la splendeur de l'Etre suprême" (KANT, 1984, p. 65). Se o cosmos é filho das leis gerais de ação da matéria, e como estas escorrem "[...] du dessein suprême, elles ne peuvent alors [...] avoir d'autres déterminations que de tendre à accomplir [...] le plan que s'est proposé la Sagesse suprême [...]" (KANT, 1984, p. 66). Esse é o estilo que "[...] la physico-théologie rénovée de 1755 pensait fournir le moyen de dépasser et de régler le conflit qui avait opposé la foi au savoir" (SEIDENGART, 1984, p. 32).

Elucidar, assim sendo, os nexos sistemáticos do universo por uma tendência natural não insinua, aos olhos de Kant, uma apologia à independência da natureza frente à providência divina. Ou seja, para Kant, aceitar que toda a ordem do universo provém "[...] des fondements naturels capables de réaliser cet ordre à partir des propriétés les plus générales et les plus essentielles de la matière [...]" (KANT, 1984, p. 66) não decreta concluir ser "[...] inutile d'en appeler à un gouvernement supérieur" (KANT, 1984, p. 66-67). Mesmo porque "[...] la matière se déterminant ellemême par la mécanique de ses forces a une exactitude certaine dans ses conséquences [...] et satisfait sans contrainte aux régles de la mesure [...]" (KANT, 1984, p. 68), ou melhor, às potências de sublimidade semeadas pelo Criador.

Mas, se "[...] la condition de toute cosmologie physique est que l'univers entier soit reconnu comme un vaste système dynamique [...]" (KERSZBERG, 1984, p. 218-219) e se o cosmos é o resultado de uma terna aliança entre uma causalidade mecânica e uma teleologia da natureza, qual o predicado do espaço (e do tempo) por sobre o qual essa totalidade material que é o mundo (a criação) se deposita e se realiza?

O modelo cosmológico da "Teoria do Céu" "[...] est construit pour répondre à cette difficulté" (KERSZBERG, 1984, p. 219). Enquanto Newton tolera, concomitantemente com o espaço absoluto (geométrico), a existência de um espaço 
relativo (que seria uma dimensão móvel do espaço inerte/imóvel e que recai em nossos sentidos devido a sua relação aos corpos) e estabelece entre "[...] cet absolu et ce relatif [...] toute la différence qui sépare les quantités mesurées elles-mêmes de leurs mesures sensibles [...]" (KERSZBERG, 1984, p. 221), Kant, por sua vez, em sua "Teoria do Céu", efetua uma distinção entre o espaço geométrico/absoluto de ancoragem newtoniana e o espaço físico, enfim, o espaço das substâncias materiais.

Além do mais, na "Teoria do Céu", Kant aparta, integralmente, o devenir cósmico de qualquer variação da essência ou do estatuto do espaço. Esse devenir é "[...] rendu entièrement possible par les seules conditions initiales internes. La matière originelle, une fois qu'elle a ainsi 'rempli' le monde, 'est' le monde, à la fois son contenu et sa structure" (KERSZBERG, 1984, p. 225). Nesse sucedimento, o "[...] monde matériel étant livré à lui-même dès l'instant de la création, il n'y a ni espace ni temps physiques qui soient au-dehors ou au-delà de lui" (KERSZBERG, 1984, p. 225).

Nesse jogo metafísico, no qual o infinito e a variedade da matéria compõem os sistemas do mundo, Kant define que "[...] l'espace et le temps vides, infinis et éternels constituent une identité infinie" (KERSZBERG, 1984, p. 226). O mundo material, este, contém “[...] une très grande diversité de plans qui servent la même fin et, corrélativement, une multiplicité de moyens et de voies vers le même but; cette diversité et cette multiplicité doivent se renouveler à chaque époque [...]" (KERSZBERG, 1984, p. 226). O universo físico, por seu turno, não é outra coisa senão a diferença infinita "[...] qui s'ouvre sans cesse vers l'identité, et ceci de proche en proche, c'est-à-dire selon une constitution systématique. Cette différence trouve son télos dans l'identité et, en retour, elle tend à la matérialiser" (KERSZBERG, 1984, p. 226).
E “[...] c'est seulement par cette ouverture que la matière 'est' quelque chose i.e. que la matière trouve son télos dans cela même qui vient à l'existence matérielle" (KERSZBERG, 1984, p. 226). E desse movimento de abertura da identidade para se transformar "[...] à autre chose qu'ellemême [...]" (KERSZBERG, 1984, p. 226) é que se organiza (ou que se funda) uma diferença. E o cosmos, materializado no espaço físico/concreto, é a consumação desse movimento da diferença rumo à identidade.

Logo, o universo "[...] se présente comme un amas indéfini de particules, à l'intérieur duquel un champ local et 'réel' de forces détermine un 'lieu' physique, en conférant à un nombre toujours croissant de ces particules un arrangement ordonée" (KERSZBERG, 1984, p. 221). E as partículas de matéria, cada uma delas, destarte, só acham sua "[...] permanence 'substantielle' [...] lorsqu'ella subit effectivement l'attraction gravitationnelle. C'est alors seulement qu'elle est un objet du monde organisé et, par suite, un objet pour la physique" (KERSZBERG, 1984, p. 221). E sua "[...] façonnement est un rapport dynamique à d'autres particules qui sont dans le même état qu'elle; de là, la possibilité d'une constitution systématique et stable" (KERSZBERG, 1984, p. 221).

Parece-nos razoável, diante dessas panorâmicas considerações, rematar que o jovem Kant, na "Teoria do Céu", faz da gradaria conceitual de Newton a substância proeminente de um sistema mecânico do mundo. Tanto que, apoiandose nas teorias newtonianas, ele "[...] prend en considération ce fait que les planètes du système solaire se meuvent dans un espace vide - ou [...] dans un espace rempli d'une matière hypothétique tellement ténue qu'elle ne manifeste aucun effet physique déterminant" (KERSZBERG, 1984, p. 235), inclusive porque, por "[...] principe, l'espace plein freine les mouvements d'une 
manière irréversible" (KERSZBERG, 1984, p. 235).

No entanto, Kant “[...] réalise qu'il n'y a aucune raison suffisante pour admettre que l'univers s'est toujours maintenu dans l'état où nous le voyons actuellement" (KERSZBERG, 1984, p. 235); e é essa atitude que lhe permite distintamente de Newton; e por intercessão da aquiescência da possibilidade de uma regeneração cíclica que se aplica ao universo em seu todo - conjugar (compatibilizar) o mecanismo $d a$ gravitação e a perenidade cósmica.

\section{E A GEOGRAFIA FÍSICA...}

Em linhas gerais, no alvorecer de seu lavor docente, Kant - empuxado pelos problemas da física do século XVIII, pela acedência (e vasta fertilidade) da filosofia natural de Newton e pelas dificuldades cominadas pela metafísica racionalistaleibniziana de Wolff - entregou-se (sem, todavia, se prender às suas indagações de detalhe, mas interessado por suas demandas de indole geral) às ciências da natureza. Como afirma, apropositadamente, Cassirer (1997, p.60-61):

[...] durante los primeros diez años de su carrera docente, vemos que lo que primordialmente le preocupa en este período es el determinar, dentro del pensamiento, la extensión del universo. Ningún otro período de la vida de Kant se halla tan dominado y caracterizado como éste por el puro "afán de acopiar materia". Vemos a nuestro filósofo desplegar una labor gigantesca encaminada, fundamentalmente, a reunir y clasificar el material de observación que había de servir de base para la nueva concepción total del mundo.
No tiene más remedio que suplir las lagunas de sus propias impresiones y experiencias recurriendo a medios secundarios de todas clases: obras de geografía y de ciencias naturales, relatos de viajes $\mathrm{e}$ informes de investigaciones. Nada, ni aun lo más nimio dentro de este campo, escapa a su atención despierta y viva. Y aunque este procedimiento de asimilación de la materia parece hallarse expuesto, y se halla, a todos los peligros que la simple recepción de observaciones ajenas lleva siempre aparejados, la falta de la percepción directa de los sentidos se compensa aquí con aquel don de "fantasía sensorial exacta" que siempre tuvo Kant. Gracias a esta facultad se agrupaban en su espíritu, formando una imagen armónica y nítida, todos aquellos rasgos sueltos recogidos por él a través de toda una serie de informes diseminados.

[...]. Y así, ayudado por estas dotes intelectuales, fué construyendo rasgo a rasgo, elemento a elemento, la imagen total del cosmos visible. La fuerza interior de su capacidad de representación y de pensamiento se encarga de ensanchar los escasos materiales que le brindan los datos directamente recogidos hasta formar una imagen del universo en que se aúnan la plenitud y la armonía sistemática. En la época a que estamos refiriéndonos predomina con mucho [...] la fuerza de la síntesis sobre la fuerza analítica y crítica. Este afán de remontarse al todo 
ejerce un poder tan acuciador en el espíritu de Kant, que la fantasía constructiva se adelanta casi siempre, en su impaciencia, a la paciente contrastación de los datos concretos. La frase "dadme materia y os construiré con ella un mundo", que el prólogo a la Historia general de la naturaleza y teoría del cielo explica y comenta con diversas variantes, representa [...] no sólo el tema especial de la cosmogonía kantiana, sino también el problema más general que se ofrece a su consideración durante este período. La estructura astronômico-cósmica es solamente [...] el resultado y la expresión tangible de una determinada fuerza fundamental del propio pensamiento kantiano.

A geografia física cumpre um cruciforme papel na edificação desta "nueva concepción total del mundo", especialmente por comunicar, a Kant, a plasticidade morfológica da superfície da Terra e por outorgar-lhe aparelhar uma "imagen total del cosmos visible", "una imagen del universo en que se aúnan la plenitud y la armonía sistemática". E essa sua ascensão ao cosmos, esse seu "afán de remontarse al todo" - fruto das abissais inquietações, instigadas em Kant (bem como em Goethe, Voltaire, Rousseau etc.), pela ocorrência do fatídico Terremoto de Lisboa, de 1755 - somente se fazia presumível devido a sua capacidade de representação, isto é, a "una determinada fuerza fundamental del propio pensamiento" apta a carregar-lhe "[...] más allá de los límites de lo empíricamente dado y conocido" (CASSIRER, 1997, p. 61).

Nessa contextura, "[...] a pesar de la alta estima en que tiene al método de las investigaciones empíricas concretas [...]" (CASSIRER, 1997, p. 65), Kant estava descomedidamente longe de "[...] emplearlo [...] de un modo exclusivo, y esto se revela [...] con mayor relieve en la tendencia general que preside totalmente sus propias investigaciones y la orientación de éstas, en la época a que nos estamos refiriendo" (CASSIRER, 1997, p. 65). Seu curso de geografia física abrolha, precisamente, dessa "[...] relación completa de interdependencia entre el empirismo y la teoría, entre la 'experiencia' y la "especulación", (CASSIRER, 1997, p. 64).

E, inegavelmente, é a "História Geral da Natureza e Teoria do Céu” (1755) a mensageira (genetriz) desse método metaempírico. Também, ela, coincidindo com "[...] toda la orientación científico-natural de la década siguiente, se halla informada en su conjunto por un interés de carácter ético-espiritual: investiga la 'naturaleza' para encontrar en ella al 'hombre", (CASSIRER, 1997, p. 65).

Essa miragem - que "[...] abarca el destino moral general del hombre y aquella suma de 'conocimientos del mundo y del hombre' que tan importante papel desempeñaban en todo programa pedagógico de la época de la Ilustración" (CASSIRER, 1997, p. 66) - é, indiscutivelmente, que administrou Kant a lecionar geografia física. O seu ensino (e o da antropologia) decorre de uma robusta valorização do saber prático do homem $e$ do mundo que permeia a filosofia e o exercício acadêmico de Kant nesse tempo. Como o próprio Kant assevera em sua "Geografia Física":

Pour ce qui est des sources et de l'origine de nos connaissances, nous puisons celles-ci soit dans la raison pure soit dans l'expérience qui, elle-même, à son tour, instruit la raison.

Les connaissances purement rationnelles sont données par 
notre raison; en revanche, c'est par les sens que nous recevons les connaissances empiriques. Mais comme la portée de nos sens ne dépasse pas le monde, nos connaissances empiriques ne dépassent pas non plus le monde présent.

Et puisque nous avons un double sens, un sens externe et un sens interne, grâce à eux, nous pouvons considérer le monde comme somme de toutes les connaissances empiriques. En tant qu'objet du sens externe, le monde est la nature et, en tant qu'objet du sens interne, il est l'âme ou l'homme (IX, 157).

Les expériences que nous avons de la nature et de l'homme constituent les connaissances $d u$ monde. L'anthropologie nous enseigne la connaissance de l'homme; nous devons la connaissance de la nature à la géographie physique ou description de la Terre. Il est vrai qu'il n'y a pas d'expériences au sens strict mais seulement des perceptions qui, prises ensemble, constitueraient 1'expérience. Et là encore nous ne prenons vraiment ce dernier terme que dans son sens courant de perceptions.

La description physique de la Terre est donc la première partie de la connaissance du monde. Elle appartient à une idée qu'on peut nommer la propédeutique de la connaissance du monde. L'enseignement de celle-ci semble encore très lacunaire. Il n'en demeure pas moins que c'est bien elle qui nous est la plus utile dans toutes les circonstances possibles de la vie. Il est donc nécessaire qu'elle se fasse connaître comme une connaissance susceptible d'être complétée et corrigée par l'expérience.

Nous anticipons notre expérience future, celle que nous ferons plus tard dans le monde, grâce à un enseignement et à un aperçu général de cette sorte qui nous donne un concept préliminaire de toutes choses. De celui qui a fait de nombreux voyages, on dit qu'il a vu le monde. Mais qui veut tirer profit de son voyage doit déjà s'en être esquissé un plan par avance et non se contener de regarder le monde comme un objet du sens externe.

L'autre partie de la connaissance $\mathrm{du}$ monde traite de la connaissance de l'homme. La fréquentation des hommes élargit nos connaissances. Il reste cependant nécessaire de s'exercer et ce se préparer à toutes les expériences futures; c'est ce que permet 1'Anthropologie. Elle permet de connaître ce qui, dans l'homme, est pragmatique et non pas spéculatif. L'homme est alors considéré non pas d'un point de vue physiologique, qui vise à distinguer les sources des phénomènes, mais d'un point de vue cosmologique [...].

Ce qui fait sérieusement défaut c'est l'apprentissage d'une mise en application des connaissances déjà acquises et d'une mise en usage de celles-ci, conforme à la fois à (IX, 158) l'entendement et aux circonstances, autrement dit, une instruction permettant à nos connaissances de trouver leur dimension pratique. Et c'est cela 
la connaissance $d u$ monde

(KANT, 1999, p. 65-67).

Com o curso de geografia física, essa propedêutica ao conhecimento do mundo, Kant cobiçava, dessa forma, retificar um descuido da juventude estudiosa que "[...] consistía, principalmente, en que se la enseñaba a razonar desde muy pronto sin poseer suficientes conocimientos históricos que pudieran ocupar el lugar de la experiéncia [...]" (KANT apud CASSIRER, 1997, p. 65-66).

E foi ocasionado pela vontade de corrigir essa lacuna que Kant resolveu-se por "[...] convertir la historia del estado actual de la tierra o la geografía en el más amplio de los sentidos en un compendio agradable y fácil de lo que podía prepararlos para una razón práctica [...]" (apud CASSIRER, 1997, p. 66). Pois que:

La enseñanza académica de Kant presentaba [...] durante esta época [...] el sello de una "urbanidad" de hombre de mundo. No podemos maravillarnos, dado el carácter enciclopédico-popular que había creído necesario infundir a esta disciplina, de que no tratase la "geografía física" "de aquel modo completo y con aquella precisión en cuanto a sus partes propios de la física y de la historia natural, sino con la curiosidad racional de un viajero que busca por doquier lo curioso, lo raro y lo bello, compara las observaciones por él reunidas y cavila y madura su plan" $[.$.$] , pero incluso$ refiriéndose a la enseñanza de las disciplinas abstractas declara que deben proponerse como meta formar "primero el hombre comprensivo, luego el hombre racional" y sólo en última línea el erudito [...].

Como vemos, Kant se orienta siempre, así en su propia formación como en su enseñanza académica, a un ideal de vasto "conocimiento práctico del hombre". Es la meta que perseguirán más tarde sus cursos de antropología: la misma que persiguieron al principio los de geografía física (CASSIRER, 1997, p. 68-69).

Um conhecimento da natureza $e$ do mundo, sob os auspícios de uma razão prática, traz em seu âmago um conato vínculo metafísico com o destino moral do homem. E, para "[...] poder llenar cumplidamente el lugar que ocupa dentro de la creación, el hombre necesita, ante todo, [...] comprenderse a si mismo como miembro de la naturaleza, pero colocado [...] por encima de ella en cuanto a su meta final" (CASSIRER, 1997, p. 66). Uma descrição da Terra (uma geografia), pois, não se desliga de um infrangível enlaçamento entre a metafísica da natureza e a física, isto é, de uma visão mediante a qual "[...] el punto de vista causal se entrelaza [...] directamente con el teleológico" (CASSIRER, 1997, p. 66).

E é em sua "História Geral da Natureza e Teoria do Céu" - opúsculo que incorpora "[...] entremezclados sin cuidado alguno, el método de la inducción propia de las ciencias naturales, el método de la medición y el cáculo matemáticos $\mathrm{y}$, finalmente, el método del pensamiento metafísico" (CASSIRER, 1997, p. 72) que, por primeira vez, intenciona Kant concordar estes dois critérios: o causal (mecânico) e o teleológico, “[...] y esto hace que la contemplación de la naturaleza conduzca al autor [...] a una teoría sobre el destino moral del hombre, la cual desemboca, a su vez, en determinados 
postulados y normas de carácter metafísico" (CASSIRER, 1997, p. 72).

\section{CONSIDERAÇÕES FINAIS}

\begin{abstract}
Com Newton, as ciências da natureza tornaram-se, praticamente, alforriadas da incumbência de dar cabo a uma representação do cosmos em sua totalidade. Sua metodologia opera segundo graus sucessivos de generalização, partindo do nosso mundo físico local e se estendendo até onde a experiência nos outorga um conhecimento factual. A "Teoria do Céu" é, primeiramente, uma reflexão metafísica sobre o alcance das leis gerais de Newton; e a idéia de cosmos que dela brota parte desse mundo físico local e exige uma ciência que o descreva; e esta é a geografia física.
\end{abstract}

Destarte, a origem do curso de geografia física de Kant insere-se na esfera da sua busca em elucubrar acerca dos fundamentos metafísicos de toda teoria física, mais notadamente, de sua pretensão em sopesar a pujança das leis físicas newtonianas em universalizar-se na edificação de uma idéia geral do universo. Como generalizar a todo o universo a única experiência local? Essa é a inquisição primordial da "Teoria do Céu"; e a geografia física não se desata dessa pergunta cosmológica, ou seja, dessa preocupação epistemológica e especulativa relativa à indole universal de toda representação possível da natureza.

Alocando-se no perímetro entre a ciência física e a filosofia, a geografia física, em seu nascimento, inscreve-se, pois, nesse esforço de Kant em instituir o regulamento epistemológico e metafísico das ciências da natureza, isto é, em preceituar os baldrames da teoria física; em conferir uma expressão física aos seus próprios fundamentos; em cravar uma teoria física sobre o conhecimento físico.

Pois, se a essência da natureza reside em sua história; o mundo físico nos é abonado de maneira imediata em nossa experiência por uma geografia. Como a cosmologia pré-crítica de Kant não se põe a responder "o que é" o universo; mas de tentar elucidar onde "ele estâ" (têmporoespacialmente) em seu devenir, uma geografia física lhe é, então, congênita. Como a natureza em sua distinção pode concordar com a totalidade material das coisas? Qual o seu espelhamento físico? Em face destas questões, parece-nos incontroverso que Kant dispõe-se, em 1756, a ensinar geografia física em decurso de seu projeto metafísico em transportar a matematização da física até perpetrar encontrar, nela, uma expressão física de seus próprios limites.

\section{NOTAS}

1 No tempo e no território (Prússia Oriental) de Kant - diga-se oportunamente - para se lecionar um dado curso, todo professor devia, imprescindivelmente, proceder de conformidade a um manual oficialmente reconhecido. Portanto, nenhum docente tinha consentimento expresso para instruir um tratado sobre determinado tópico de ensino em seu próprio nome. Como não havia, na época, uma escritura que Kant pudesse valer-se em suas palestras de geografia física - que foi a segunda especialidade mais doutrinada por Kant no transcorrer de sua faina professoral, imediatamente após a lógica e a metafísica - ele resolveu por lavrar um resumo a este intento; e, por intervenção de um decreto de von Zedlitz de 16/10/1778, foi-lhe anuída a licença para despendê-lo em suas alocuções geográficas (COHEN-HALIMI, 1999). Esses registros minutados, organizados por Kant (que manifestavam, em seu teor - além de uma dilatada e inventiva imaginação - um profuso conhecimento das ciências naturais e, igualmente, uma abundosa quantidade de informações geográficas proveniente de assíduas leituras de relatos de viagens, de 
descrições de expedições científicas, de jornais, de revistas etc.), permaneceram, por decênios, sem qualquer tratamento metódico. Kant não aquiescia publicar, ele mesmo, este acervo de notas, pois que, aprontar uma obra a partir dos originais aproveitados (utilizados) em seu curso, afigurava-se, a ele, no findar de sua vida, uma execução praticamente irrealizável (COHEN-HALIMI, 1999). Foi que, mais ou menos em 1800, Friedrich Theodor Rink (1770-1811) e Gottlob Benjamin Jäsche (1762-1842) - encarregados, pelo professor-filósofo, "[...] de réviser et de réorganiser ses papiers, dont la masse avait considérablement augmenté" (RINK, 1999, p. 63) - se toparam, "[...] lors de ce travail et contre toute attente de Kant lui-même [...]" (RINK, 1999, p. 63), com “[...] presque trois cahiers de géographie physique, rédigés à différentes époques [...]" (RINK, 1999, p. 63). Kant, ante esta inesperada oportunidade, adjudicou encargo a Rink, um remoto e estimado aluno seu, para que este efetuasse a empresa editorial destes extratos no formato de livro, o que sucedeu em 1802. Logo, "It is the Rink edition that is today known as the Physische Geographie, later incorporated into the Akademie Ausgabe of Kants gesammelte Schriften [...]" (ELDEN, 2008, p. 5). O cunho serôdio de sua aparição nos permite discernir a motivação que dirige Cohen-Halimi (1999, p.10) a inferir que "[...] ce Cours de Géographie physique accompagna pour ainsi dire clandestinement tout le parcours philosophique de Kant [...]”. Entretanto, não obstante esse tardamento, as investigações filológicas de E. Adickes "[...] permettent de tenir le Cours de Géographie pour une oeuvre kantienne authentique, même s'il a fallu la reconstituter en ajoutant au manuscrit de Kant les notes prises par ses étudiants durant les cours [...]" (COHEN-HALIMI, 1999, p. 9). Dessa maneira, é no alvor do século XIX, na antiga Prússia Oriental - mais exatamente na então urbe de Königsberg, à beirada do Mar Báltico - que a "Physische Geographie" foi publicada; justamente quando, no ultimar de sua vida e fruindo de opulenta auréola em toda Europa savante, Kant deparava-se com a fatalidade de decidir-se acerca de fração de sua obra da qual o porvir continuava sendo, até aquela ocasião, não resoluto e cujo zelo editorial se fazia inteiramente indispensável: suas correspondências; seus comentários manuscritos nos compêndios que empregava como professor; as transcrições de seus cursos redigidas por estudantes etc. (FIGUEIREDO, 2005).

\section{REFERÊNCIAS}

CASSIRER, Ernst. Kant, vida y doctrina. Bogotá: Fondo de Cultura Económica, 1997.

COHEN-HALIMI, Michèle. Le Géographe de Königsberg. In: KANT, Immanuel. Géographie. Physische Geographie. Paris: Aubier, 1999. p. 9-40.

ELDEN, Stuart. Reassessing Kant's geography. Journal of Historical Geography (2008), doi: 10.1016/j.jhg.2008.06.001.

FIGUEIREDO, Vinícius de. Apresentação. In: KANT, I. Escritos pré-críticos. São Paulo: Editora UNESP, 2005.

HÖFFE, Otfried. Immanuel Kant. São Paulo: Martins Fontes, 2005.

KANT, Immanuel. Histoire Générale de la Nature et Théorie du Ciel. Paris: Librairie Philosophique J. Vrin, 1984. p. 61-203.

\section{Geographie. Physische}

Geographie. Paris: Aubier - Bibliothèque Philosophique, 1999.

KERSZBERG, Pierre. Post-Face. La Création en movement. Essai sur le sens 
philosophique d'une interrogation

cosmologique fondamentale dans la Théorie

du Ciel. In: KANT, Immanuel. Histoire

Générale de la Nature et Théorie du Ciel.

Paris: Librairie Philosophique J. Vrin, 1984. p. 205-259.

RINK, Thomas. Prólogo do Editor. In: KANT, Immanuel. Géographie. Physische Geographie. Paris: Aubier, 1999. p. 61-63.

SEIDENGART, Jean. Avant-Propos. Genese et structure de la cosmologie kantienne précritique. In: KANT, Immanuel. Histoire Générale de la Nature et Théorie $d u$ Ciel. Paris: Librairie Philosophique J. Vrin, 1984. p. 7-59. 